\title{
(Des)classificando os "inclassificáveis": considerações sobre os faits divers e suas representações de tragédias anônimas na Capital Federal no início do século $\mathbf{X X}^{1}$
}

\author{
Isadora Luiza Francisca Alves FLORES ${ }^{2}$ \\ Andrea CIACCHI ${ }^{3}$
}

\begin{abstract}
Resumo:
O artigo elenca algumas considerações sobre o gênero jornalístico fait divers, postulando-o como um aporte para reflexão da ciência histórica. Para tal, o texto apresenta o conceito de representação, para, depois, introduzir a conceituação do fait divers e, então, dispor de análises de algumas das operações de classificação implícitas nessas narrativas. Os esforços interpretativos têm como base um corpo de notícias publicadas no diário Correio da Manhã, no primeiro quinquênio do século XX na cidade do Rio de Janeiro. Nesse empreendimento, recorre-se aos conceitos de Chartier (1991) e Pesavento (2006), sobre representações, e às contribuições de Ferro (1983), Meyer (1996) e Guimarães (2013) para compreender as especificidades desse fenômeno midiático, desde suas origens na tradição oral francesa até o seu desenvolvimento no Brasil do início do século passado.
\end{abstract}

Palavras-chave: História do Brasil; Primeira República; imprensa; Correio da Manhã.

\section{Classifying the "unclassifiable": considerations about faits divers and their representations of anonymous tragedies in the Brazilian Federal Capital at the beginning of the 20th century}

\begin{abstract}
:
This article aims to study the journalistic genre known as fait divers in order to highlight its potential as an object of historical analysis. The following text firstly presents the concept of representation, and then introduces the journalistic genre of the fait divers while analyzing the social classifications implicit by these narratives. These interpretative efforts are limited to five reports published in the Brazilian newspaper Correio da Manhã, in the first quinquennium of the 20th century at the city of Rio de Janeiro. In this paper, concepts of Chartier (1991) and Pesavento (2006) on representations and the contributions of Ferro (1983), Meyer (1996) and Guimarães (2013) are used to understand the specificities of this media phenomenon, from its origins in the French oral tradition to its development in the Brazil of the beginning of the 20th century.
\end{abstract}

Keywords: Brazilian History; First Brazilian Republic; press; Correio da Manhã.

\footnotetext{
${ }^{1}$ O presente trabalho é oriundo da dissertação defendida em 2018 por Isadora Luiza Francisca Alves Flores sob orientação do Prof. Dr. Andrea Ciacchi. Ver mais em: FLORES, Isadora Luiza Francisca Alves. Faits Divers: narrativas de transgressão e crime no Rio de Janeiro do início do século XX (1901-1904). 2018. Dissertação de Mestrado (Programa de Pós-Graduação Interdisciplinar em Estudos Latino-Americanos) - Universidade Federal da Integração Latino-Americana (Unila), Foz do Iguaçu, 2018.

2 Doutoranda do Programa de Pós-Graduação em História da Universidade Estadual do Oeste do Paraná (Unioeste), mestre em Estudos Latino-Americanos pelo Programa de Pós-Graduação Interdisciplinar em Estudos Latino-Americanos (PPG-IELA) pela Universidade Federal da Integração Latino-Americana (Unila). E-mail: isadora94flores@gmail.com.

${ }^{3}$ Professor da Universidade Federal da Integração Latino-Americana (Unila), doutor em Estudos Ibéricos pela Universidade de Bolonha, pós-doutor em Antropologia pela Universidade de Campinas (Unicamp) e pós-doutor também em Antropologia pela Universidade de Roma "La Sapienza”. E-mail: andrea.ciacchi@unila.edu.br.
} 


\title{
Clasificando lo "inclasificable": consideraciones sobre los faits divers y sus representaciones de tragedias anónimas en la Capital Federal a principios del siglo $\mathrm{XX}$
}

\begin{abstract}
Resumen:
Este artículo tiene como objetivo presentar algunas consideraciones sobre el género periodístico fait divers, postulándose como un aporte a la reflexión de la ciencia histórica. Con este fin, el texto introduce brevemente el concepto de representación, luego introduce el concepto de fait divers para entonces analizar algunas de las operaciones de clasificación implícitas en estas narrativas. Los esfuerzos interpretativos se basan en un conjunto de reportajes publicados en el diario Correio da Manhã en la ciudad de Río de Janeiro en los primeros cinco años del siglo XX.Son usados los conceptos de Chartier (1991), Pesavento (2006), sobre las representaciones, y los aportes de Ferro (1983), Meyer (1996) y Guimarães (2013) para comprender las particularidades de este fenómeno mediático, desde sus orígenes en la tradición oral francesa hasta su desarrollo en Brasil a principios del siglo pasado.
\end{abstract}

Palabras clave: Historia de Brasil; Primera República; prensa; Correio da Manhã.

\section{Introdução}

Em 06 de fevereiro de 1903, o jornal carioca Correio da Manhã publicou, na seção "Na Polícia e nas Ruas", destinada a notícias centrados em crimes e mistérios, um faits divers intitulado "Mulher Agredida - A Navalha - Em Bemfica" (Figura 1). A manchete em negrito da citada matéria adiantava para seus leitores a vítima, a arma e o local do crime, que seria reconstruído sensacionalmente no corpo da notícia.

A notícia compôs uma apresentação nada lisonjeira de sua protagonista, cuja desqualificação já começaria na "cabeça" do texto. Corina, a vítima, foi então categorizada como uma "amestrada na vagabundagem", devido às supostas múltiplas passagens pelo "xadrez" e episódios de bebedeira. Na composição da narrativa, a conduta da menor de idade foi investida de importância para apreensão do crime, propondo certa relação de causalidade entre sua suposta prévia "vagabundagem" e a violência por ela sofrida. Uma vez antecedidos pela desqualificação de "vagabunda conhecida", os episódios elencados nos antecedentes de Corina (passagens pela polícia, embriaguez, ter se "deixado" "conquistar" por um desconhecido) desvelam-se indicativos das disputas sociais que então permeavam as construções de juízos sobre as condutas de mulheres cariocas.

\footnotetext{
${ }^{4}$ Segundo consta no livro Recordações do Escrivão Isaías Caminha, de autoria de Lima Barreto, que trabalhou em jornais no início do século XX, "Cabeça se chama nos jornais às considerações que precedem uma notícia. Feita com a moral de Simão de Nântua e a leitura dos folhetins policiais, a 'cabeça' é a pedra de toque da inteligência dos pequenos repórteres e dos redatores anônimos” (BARRETO, 2008, p. 118).
} 
Figura 1 - Jornal Correio da Manhã, Rio de Janeiro, n. 605, p. 2, 6 fev. 1903.

Malier nggrellitia--X navalha--Rm Bemflea

E' varatunda conliecida a nullher que accade pelo nome de Corina Maria da Concoieño.

Nío obstante contar apenas 19 annos do

edade, Coilna já está amestriula na vacabun

dagom, seudo sempre encontrala cat Sito Clitistovio $\mathrm{cm}$ astado de embriaguez, o gie

lhe tem feito dar diversas entradas no $\mathrm{ka}$.

drez da s delezacia urbana.

Ilontem deisoll-so Colina vencer pelos canstantes galanteios que lie fez unt creouia sen desconhecido, que a convidou a pas. seiar.

Partindo de S Christovĩo, foi ella conduzida pelo sea conruistador a Beinftea, onde sc deu uma discordia entre os passeiantes.

liaes foran as conversas que teve o creoulo com a rapariga, que esta sentindo-se offendida, passou a insultai-o.

Enraivecido, o d. Juan sacou de uma navalia e ceriu, na coxa esquerda, a sua companlidia du devas cio rocturno.

Consummacia a aggressän, cvadin-so o criminoso, dicigindo*se a ollentida a $11 \cdot \mathrm{de}$ legacir uribars, onde relatou of facto.

Corina que reside a rua D. Anna Nery 27

foi enviada a Santa Casa de Misericordia.

listi abeito o inquerito sobre esta occor. rencia.

Fonte: Acervo da Hemeroteca Digital da Biblioteca Nacional, disponível em http://memoria.bn.br/DocReader/docmulti.aspx?bib=089842\&pesq=.

A partir de notícias como a narrativa do infortúnio de Corina, propõe-se o presente artigo. Nesse sentido, objetiva-se contribuir com a divulgação do gênero jornalístico fait divers como aporte para o estudo historiográfico de seus contextos de produção. Segundo Pesavento (2006), a representação é a prática humana de "re-apresentar" o mundo, seja "[...] pela linguagem e pela forma, e também, pela encenação do gesto ou pelo som - , a representação dá a ver e remete a uma ausência" (PESAVENTO, 2006, p.49). A ausente Corina foi representada para os leitores do Correio como uma "vagabunda conhecida". Ou seja, sua maneira de estar no mundo foi significada pelo autor da notícia, explicitando assim, uma (des)qualificação possível, mas não necessariamente unívoca, dessa vivência feminina em tal conjuntura histórica.

Segundo Chartier (1991, p. 183), a representação permite a articulação de três modalidades de relação com o mundo social:

[...] de início, o trabalho de classificação e de recorte que produz configurações intelectuais múltiplas pelas quais a realidade é contraditoriamente construída pelos diferentes grupos que compõem uma 
sociedade; em seguida, as práticas que visam a fazer reconhecer uma identidade social, a exibir uma maneira própria de ser no mundo, a significar simbolicamente um estatuto e uma posição; enfim, as formas institucionalizadas e objetivadas em virtude das quais "representantes" (instâncias coletivas ou indivíduos singulares) marcam de modo visível e perpétuo a existência do grupo, da comunidade ou da classe.

Não excluindo as possíveis apropriações e ressignificações que podem sofrer temporalmente, Chartier (1990) enfatiza que as representações são percepções do social e, como tal, não são discursos neutros, pelo contrário, produzem e respondem às estratégias e práticas (sociais, escolares, políticas). Para o autor, as investigações sobre as representações deveriam, portanto, localizá-las em relação a um campo de concorrências e competições cujos desafios se enunciam em termos de poder e dominação (CHARTIER, 1990).

A mesma perspectiva teórica também embasa a análise proposta por Guimarães (2013), na obra Notícias Diversas: suicídios por amor, leituras contagiosas e cultura popular em São Paulo dos anos dez. A partir da afirmação de Chartier (1990) de que o real seria condicionado pela maneira como os homens o pensam e o transpõem, Guimarães (2013) postula o conceito de representação como a chave para a decifração dos faits divers. Com base em tais perspectivas, o presente trabalho assume as notícias dessa natureza não como descrições estritamente factuais da realidade ou mesmo instrumentos puros de ordenamento social, mas como aportes para reflexão histórica de como diferentes estatutos e realidades sociais foram pensadas, construídas, nos termos de Chartier (1990), "dadas a ler".

\section{Faits divers}

Em uma análise diacrônica, o termo francês fait divers, em tradução livre, "fatos diversos", foi utilizado pela primeira vez em 1863, no jornal de Moïse Polydore Millaud (18131871), Le Petit Journal (MEYER, 1996, p.97). Todavia, o relato melodramático de crimes reais não foi necessariamente uma novidade entres os impressos franceses, já sendo verificado agrupado a dicas de beleza, pequenas histórias e receitas no "feuilleton", ${ }^{5}$ dos eruditos e sisudos jornais do Primeiro Reinado (MEYER, 1996, p.57).

As matrizes desse fenômeno comunicacional, conforme Guimarães (2013) e Meyer (1996), seriam anteriores mesmo ao surgimento, propriamente dito, de jornais, remetendo às antigas tradições orais de sociabilização de informação. Tradições cujas afetações

\footnotetext{
${ }^{5} \mathrm{O}$ feuilleton designa o rez-de-chaussée, rés do chão, ou rodapé, espaço localizado geralmente na primeira página, com uma finalidade específica de apresentar entretenimento, podendo ser composto de folhetins, receitas, notícias frívolas, etc.
} 
características da sua oralidade foram cooptadas e adaptadas, inicialmente, pela produção de folhetos populares, como os occasionales franceses, que, para Guimarães (2013, p. 5), teriam surgido no século XV, "constando os primeiros registros de 1488 " e trazendo "relatos nos quais predominavam o exagero e a invenção". Modelo que teria permanecido com sucesso no século XIX:

[...] em pequenos jornais populares de uma só página, estampados apenas em uma face, com o nome pejorativo de canard que, metaforicamente, significa "falsa notícia". [...] o faits divers é herdeiro direto dos canards. Todos esses tinham sua raiz nas nouvelles, histórias contadas oralmente por um nouvelliste em praça pública desde tempos remotos (GUIMARÃES, 2013, p.56).

Segundo Meyer (1996), um dos grandes trunfos de Millaud e seu Petite Journal foi adaptar tradições impressas oriundas da nouvelle, prática oral que a autora caracteriza a partir da recepção do público, ativamente responsável na sua composição.

Antes de ser aprisionada nas páginas do jornal, a crônica ou nouvelle era uma forma de informação oral, transmitida por um nouvelliste, em cima de um pequeno palanque, nas ruas da cidade [...] ou na praça da aldeia, que contava para o público à sua volta as últimas histórias, verdadeiras ou fantasiosas, que corriam pelo campo ou pela cidade. Estas eram repetidas de nouvelliste em nouvelliste, o que implicava sucessivas modificações, fixando-se numa versão que correspondia à demanda da audiência que também intervinha, modificava, comentava, passava-as adiante. Mesmo impressas nos canards ou occasionnales, as notícias veiculadas nos meios populares guardavam forte marca de oralidade. O público tinha, portanto, um papel ativo na confecção dessas notícias (MEYER, 1996, p.101).

De forma que, além de ancorar cultural e historicamente o "gosto quase nacional por ficção e verdade romanceada", verificado na França em seu Segundo Reinado, Meyer (1996, p. 97) também atribui o processo de "aprisionamento" da nouvelle à inovação técnica que marcou a produção impressa do período. Conjugação de fatores que, na perspectiva da autora, acarretou o surgimento da petite presse, segmento popular encabeçado pelo Le Petite Journal, de Millaud (MEYER,1996).

Diante de tiragens expressivas, Meyer (1996) postula a "genialidade" do pioneiro Millaud em reconhecer como entreter seu público. Nesse sentido, Le Petite Journal suportava tanto a adaptação de antigas tradições de comunicação popular, como a vinculação de novidades, demonstrando, assim:

[...] cuidado e sensibilidade à demanda do novo público específico que queria atingir. Não só pelos aspectos materiais do jornal - preço, formato, distribuição -, como por seu conteúdo. Ele soube aliar uma novidade, o 
folhetim, cujo consumo fora amplamente confirmado pelo sucesso da fórmula do jornal-romance, o qual, aliás, acabou suplantado pelo novo jornalismo de massa, a uma tradicional modalidade de informação popular, reinterpretandoa e rebatizando-a. Trata-se da nouvelle, ou canard, ou chronique, a que deu novo nome: faits divers, ou seja, uma notícia extraordinária, transmitida em forma romanceada, num registro melodramático, que vai fazer concorrência ao folhetim e muitas vezes suplantá-lo nas tiragens (MEYER, 1996, p. 97).

Devido ao sucesso do Le Petite Journal, a consequente difusão da petite presse e do gênero fait divers, em finais do século XIX, tal expressão passa a ser usada como rubrica sob a qual eram noticiados fenômenos que, de alguma forma, desafiavam a ordem cotidiana e/ou natural das coisas. Percepção evidenciada, também, pelo significado concedido à expressão pelo Grand Dictionnaire Universel du XIX e siècle, léxico de ambições enciclopédicas de Pierre Larousse:

Sob esta rubrica, os jornais reúnem com arte e publicam regularmente notícias de todo tipo que correm o mundo: pequenos escândalos, crimes horrendos, suicídios por amor, pedreiros caindo do quinto andar, assaltos à mão armada, chuva de gafanhotos ou de sapos, naufrágios, incêndios, inundações, aventuras burlescas, raptos misteriosos, execuções capitais, casos de hidrofobia, antropofagia, de sonambulismo e de letargia. Ampla gama de atos de salvamento e fenômenos da natureza, como bezerros de duas cabeças, sapos de quatro mil anos, gêmeos xifópagos, crianças de três olhos, anões extra-ordinários, etc. (LAROUSSE, 1872 apud ANGRIMANI, 1995, p. 25).

Todavia, mais que uma rubrica, a expressão faits divers também recobre outros sentidos, conforme o prefácio do catálogo da exposição sobre esse gênero jornalístico organizada em 1982, pelo Museu Nacional de Artes e Tradições Populares de Paris:

O termo faits divers tornou-se hoje de uso tão banal que nem nos ocorreria interrogar-nos sobre a realidade do que ele recobre. É utilizado todos os dias como se designasse um conceito bem definido que nos viria naturalmente ao espírito. Trata-se, no entanto, de expressão relativamente recente. Surgiu em Le Petit Journal, em 1863, e não consta que tivesse sido utilizada anteriormente. Até então falava-se, como diziam Balzac ou Nerval, de "canards", ou de "faits Paris", ou de "nouvelles" que são qualificadas de "curiosas", "singulares" ou "extraordinárias". [...] O conceito de faits divers não se impõe, portanto per si. É uma noção aproximativa que deve ser manejada com cautela. A própria expressão faits divers não designa, portanto somente uma atividade de distribuição das notícias entre as rubricas de um jornal, ou um tipo de informação, mas também, com uma conotação explicitamente pejorativa, uma categoria particular de acontecimentos (MUSÉE NATIONAL DES ARTS ET TRADITIONS POPULAIRES DE PARIS, 1982 apud MEYER, 1996, p. 98).

Categoria particular de acontecimentos que foi caracterizada pelo semiólogo Barthes (1977) como procedente da “classificação do inclassificável”. O semiólogo localiza a conotação 
pejorativa à qual o catálogo se refere na natureza anormal dos acontecimentos objetos desse gênero jornalístico:

\begin{abstract}
Eis um assassinato: se é político, é uma informação, se não o é, é uma notícia. Por quê? Poder-se-ia acreditar que a diferença é aqui a do particular e do geral ou, mais exatamente, a do nomeado e do inominado: a notícia geral (pelo menos a palavra francesa faits divers parece indicá-lo) procederia de uma classificação do inclassificável, seria o refugo desorganizado das notícias informes; sua essência seria privativa, só começaria a existir onde o mundo deixa de ser nomeado, submetido a um catálogo conhecido (política, economia, guerras, espetáculos, ciências, etc.); numa só palavra, seria uma informação monstruosa, análoga a todos os fatos excepcionais ou insignificantes, em suma, inomináveis, que se classificam em geral pudicamente sob a rubrica dos Varia, tal como o ornitorrinco que deu tanto trabalho ao infeliz Lineu (BARTHES, 1977, p. 271).
\end{abstract}

Barthes (1977) estabelece uma tipologia estrutural básica dos faits divers, analisando a relação estabelecida entre a "forma" e "conteúdo" dessas narrativas (BARTHES, 1977, p. 271). Análise que resulta na organização de tal tipologia a partir de duas categorias e suas correspondentes subdivisões. A primeira delas seria a Causalidade, subdividia em Causa Perturbada e Causa Esperada; e a segunda, a Coincidência, também subdivida, em Repetição e Antítese (BARTHES, 1977, p. 271-274). Todavia, aqui não se pretende uma análise de faits divers em função de uma percepção fundamentalmente estrutural dessas narrativas. $\mathrm{O}$ presente texto alinha-se à aproximação aos faits divers proposta por Guimarães (2009; 2010; 2013; 2014), em sua extensa produção a respeito do gênero.

Segundo a autora, as trajetórias humanas narradas nessas notícias se relacionam a aspectos coletivos da sociedade em que foram produzidas, devido, também, à sua veiculação por órgãos da imprensa que, em alguma instância, respondem a expectativas de legibilidade e verossimilhança (GUIMARÃES, 2013, p. 60).

[...] tanto faits divers como os folhetins aparentam não requerer referências dadas de antemão ao leitor, não exigir um contexto. São narrativas que, a um primeiro olhar, dão a impressão de encerrarem em si mesmas, pois são bastante legíveis em qualquer situação, ainda que muitos anos se passem após o ocorrido. Mas como já foi dito, a notícia tem uma historicidade (GUIMARÃES, 2013, p. 64).

Nesse sentido, recorre-se aqui também a algumas considerações de Ferro (1983) publicadas na apresentação do número da Revista dos Annales dedicada aos faits divers. Também citado por Guimarães (2013), o autor francês assume o gênero jornalístico dos faits divers como um sintoma "cujo significado pode variar ao longo do tempo e através das culturas" 
(FERRO, 1983, p. 822). Propõe ainda que a história dos faits divers comportaria muitas variáveis, e que sua natureza "pode igualmente se modificar", tal como a sua relação com o corpo social, sua função e seu funcionamento (FERRO, 1983, p. 822). A título de exemplo, o autor cita a suspensão dos faits divers no período da Revolução Russa, em 1917, tempo de transição em que toda a informação acabava sendo reavaliada e classificada de outra forma:

Visto que a lei não é mais a lei, um crime não é mais um crime. As fronteiras desaparecem entre o cotidiano, ordinário e extraordinário. Um mundo oscila nesta sociedade que se transforma, é o preso que diz para o guarda «Eu estava lá para você se tornar um homem livre» (FERRO, 1983, p. 823, tradução nossa). ${ }^{6}$

À luz da experiência de tal ruptura, o historiador observa o seu reestabelecimento em termos outros, resultantes da experiência do novo regime político da União Soviética. Nesse sentido, Ferro (1983) observa que, embora os faits divers possuíssem uma rubrica (a khronika), a sua natureza apresentava desvios daquela observada no Ocidente, em função justamente das especificidades do funcionamento social de tal conjuntura (FERRO, 1983). Considerando a importância de tais contextualizações, alguns apontamentos a respeito do aparecimento desse gênero jornalístico na imprensa nacional se fazem necessários.

O fenômeno do sensacionalismo impresso caracterizado pela vinculação de narrativas melodramáticas de transgressão não foi exclusivo do desenvolvimento da imprensa francesa. De maneira que, segundo Guimarães (2013, p. 58), “os faits divers tiveram predecessores por todos os países em que a imprensa se desenvolveu, seja desde a invenção na Europa, seja nos séculos seguintes na América". Teriam sido constatados movimentos similares nas tradições impressas de outros países, merecendo especial ênfase a anglo-saxã, em que ganharia proporções expressivas (GUIMARÃES, 2013, p. 57). No artigo "Sensacionalismo e modernidade na imprensa brasileira no início do século", também de autoria de Guimarães (2009), é possível perceber que os faits divers chegam à imprensa brasileira na passagem do século XIX para o XX, pela via francesa, mas já "com características da americanização" (GUIMARÃES, 2009, p. 239).

Para a pesquisadora, "apesar do estilo americano de se fazer jornal chegar com força ao Brasil somente após os anos 1920, ele já estava presente antes disso, indiretamente e sob moldes

\footnotetext{
6 "Puisque la Loi n'est plus la loi un crime n'est plus un crime. Les frontières disparaissent entre le quotidien et événement ordinaire et extraordinaire. Un monde bascule - dans cette société qui se retourne est le détenu qui dit au gardien étais "là pour que tu deviennes un homme libre" (FERRO, 1983, p. 823).
} 
franceses, no faits divers" (GUIMARÃES, 2009, p. 239). Influência essa percebida pela própria historiografia francesa, que, segundo Guimarães:

[...] admite que os diálogos entre a imprensa francesa e anglo-saxã eram intensos, tendo esta última, imprimido seu estilo sensacionalista a toda imprensa ocidental. $\mathrm{Na}$ tentativa de definir os faits divers, portanto, temos um conceito fugidio, que soma o escândalo e o absurdo dos canards com as enquetes de base anglo-saxã (que ficou na Europa como "jornalismo") criando por fim, uma "reportagem à francesa" que é a característica precisa de um momento em particular, o fim do século XIX (GUIMARÃES, 2013, p. 58).

Ainda no que diz respeito às especificidades nacionais dos faits divers, Guimarães (2010, p. 285) também aponta que os jornais cariocas foram os primeiros a publicá-los. Não obstante, Guimarães (2010) alerta que os jornais cariocas não entrariam em uma fase mais profissional até 1910, período a partir do qual os faits divers ganhariam seções exclusivas em quase todos os diários (GUIMARÃES, 2010, p. 286). Contudo, mesmo antes desse marco, a autora refere o Correio da Manhã como recheado de "casos de crimes e eventos cotidianos contados à maneira de romances" (GUIMARÃES, 2010, p. 286). Conforme se observa ao longo de prévia pesquisa (FLORES, 2018) no citado diário, tais reportagens seriam concentradas em uma seção própria intitulada "Na Polícia e Nas ruas", já a partir de setembro de 1902.

A partir da compreensão da percepção do Correio como um veículo privilegiado para o estudo dos faits divers, Guimarães (2014, p. 124), em "Primórdios da história do sensacionalismo no Brasil: os faits divers criminais", caracterizaria o Correio como "muito sensacionalista", afirmando que reportagens desse gênero, ainda no primeiro ano da publicação, chegariam a ocupar $40 \%$ de sua superfície. Em função justamente do aparente expressivo investimento criativo e material disposto pelo seu corpo editorial em produzir faits divers, o Correio da Manhãa, jornal de pretensões populares (BARBOSA, 2007; GARZONI, 2009, 2011), e oposicionismo virulento ao governo federal (SODRÉ, 1999; MARTINS; LUCA, 2006), demonstra-se como um pertinente aporte para a percepção do imaginário social da virada do século XIX para o XX, no que toca à transgressão e criminalidade.

Narrativas que, tal como sugere Ferro, são aqui tomadas como sintomáticas de crises da malha social e dos sistemas de valores da sociedade em que foram produzidas. Tratando-se, especificamente, do Rio de Janeiro no início do século XX, remonta-se a uma cidade polo de produção científica no país, mas exuberante em desigualdades. Sem embargo, que homens e mulheres cariocas figurassem esquadrinhados e com suas constituições biológicas acrescidas de significados sociais em tratados e monografias, condutas higiênicas estipuladas a eles por 
médicos e juristas nem sempre compatíveis com a realidade material da então capital da República.

Tendo em vista a permeabilidade do discurso jornalístico a esses discursos, é evidente aquilo que Guimarães (2013) caracteriza como o papel moralizador dos faits divers, sua

[...] função de termômetro do que é ou não é admitido por esta sociedade específica. A volta exaustiva e diária a uma mesma estrutura narrativa serve para reafirmar esse imaginário que, presente na sociedade, projeta nas representações. Em torno dos personagens existem convenções que os circunscrevem a papéis preestabelecidos. E cada uma das ocorrências [...] resulta em narrativas ao mesmo tempo muito parecidas e que consolidam tais papéis (GUIMARÃES, 2013, p. 63).

Tal percepção foi de fundamental importância para a análise da segunda página de edição do Correio da Manhãa, de número 19, publicada em 3 de julho de 1901 (Figura 2).

Figura 2 - Jornal Correio da Manhã, Rio de Janeiro, n.19, p.2., 3 jul. 1901

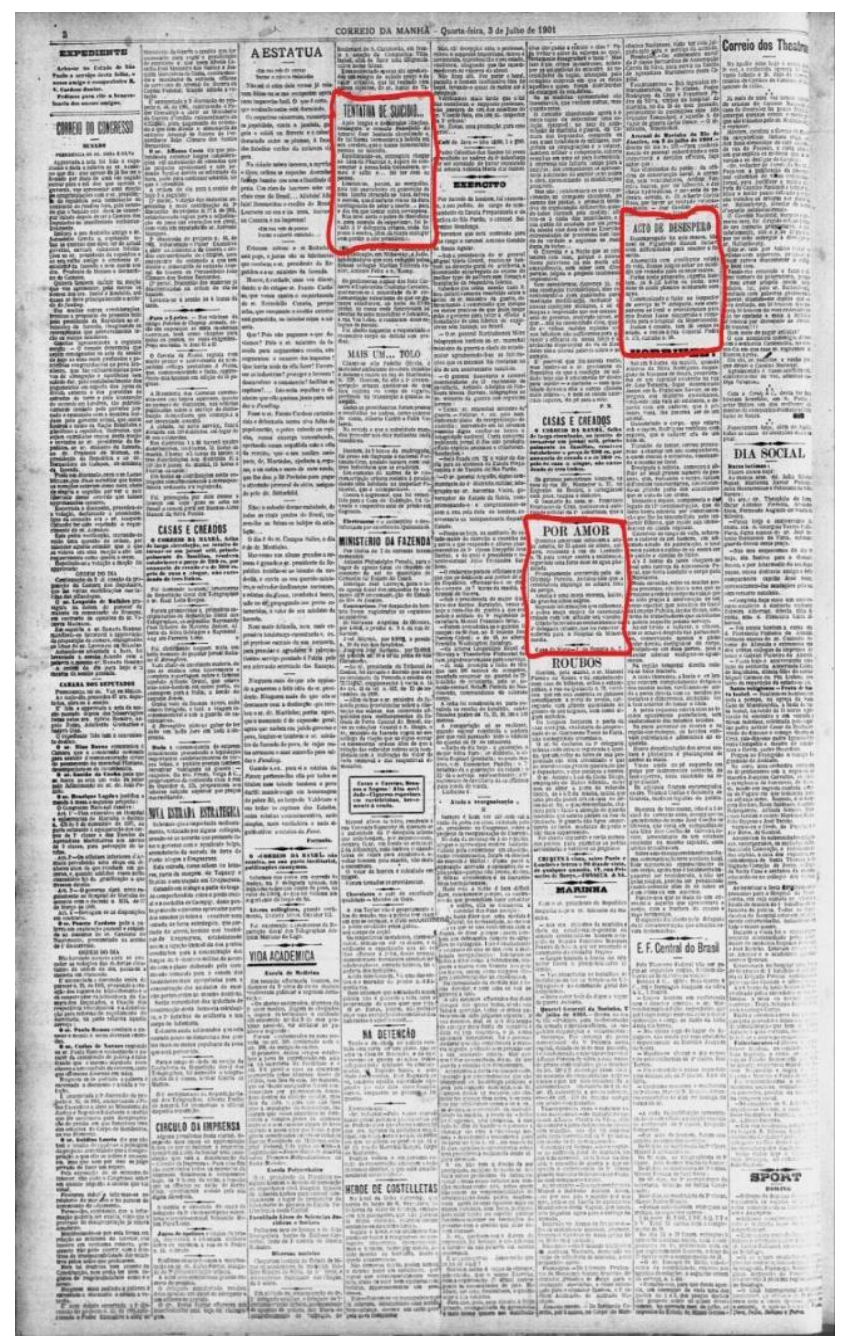

Fonte: Acervo da Hemeroteca Digital da Biblioteca Nacional, disponível em http://memoria.bn.br/DocReader/docmulti.aspx?bib=089842\&pesq= 1 . 
Na página 2 verifica-se três faits divers voltados para tentativas de suicídio e localizados de maneira próxima. Narrativas cujas especificidades permitem vislumbres de algumas lógicas que orientavam certas idealizações dos padrões normativos referentes aos seus protagonistas.

Figura 3 - Jornal Correio da Manhã, Rio de Janeiro, n.19, p. 2, 3 jul. 1901

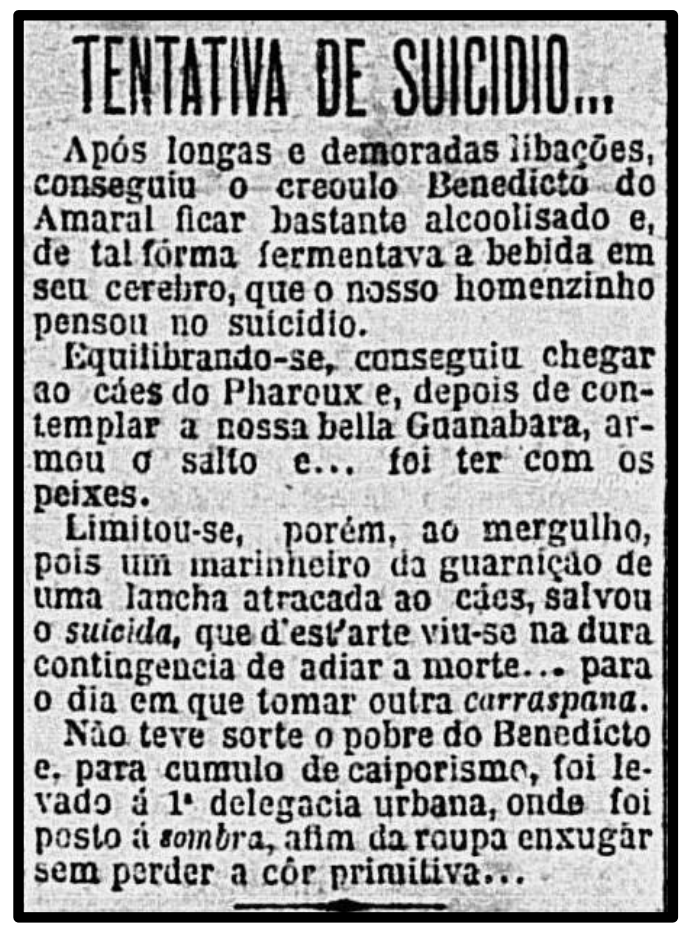

Fonte: Acervo da Hemeroteca Digital da Biblioteca Nacional, disponível em http://memoria.bn.br/DocReader/docmulti.aspx?bib=089842\&pesq=

Observando o texto na Figura 3, verifica-se que na narração da tentativa de suicídio do "creoulo" Benedicto do Amaral, a suposta "fermentação da bebida" no seu cérebro é proposta como causa explicativa de sua tragédia. Julgamento que possibilita o vislumbre de como então o uso dessa substância, principalmente na forma da "cachaça", poderia ser significado como um deflagrador/demarcador da degeneração, sobretudo entre os indivíduos das classes mais pobres (ADIALA, 2011, p. 93-100). Ao analisar as operações narrativas que repetidamente diminuem Benedicto, menosprezando sua suposta tentativa de suicídio, percebe-se também uma desqualificação da sua condição de homem negro.

Nesse sentido, o comentário a respeito da cor da sua "roupa" não parece uma simples observação quanto ao estilo do suicida, mas uma ironia que não por acaso evoca o termo "primitivo". Segundo a historiografia voltada às décadas finais do século XIX e iniciais do XX (CHALHOUB, 2001; ESTEVES, 1989; SCHWARCZ, 2005), nesse período, os debates a respeito da identidade nacional pautaram-se também por discursos e teorias racistas, que 
percebiam com preocupação a constituição da população nacional. O uso da palavra "primitivo" responde a um contexto histórico marcado também pela crescente divulgação de teorias científicas de caráter evolucionista e, como tal, racistas, que já insidiam nos centros de produção de conhecimento científicos brasileiros a partir de 1870 (SCHWARCZ, 2005, p. 57). Centros esses em que se destacou a Faculdade de Medicina do Rio de Janeiro, na qual alguns dos jovens repórteres e redatores envolvidos na produção dessas notícias estudavam (BARBOSA, 1997).

Em poucas linhas, o intento suicida de Benedito é esvaziado de tragicidade, reportado como um "capoirismo", consequente da fermentação da bebida e causa de sua prisão. Já o segundo fait divers na ordem de leitura, ao contrário daquele centrado na tentativa de suicídio de Benedicto do Amaral, apresenta já no seu título a suposta motivação por trás da tentativa de suicídio protagonizada por uma jovem de 23 anos (Figura 4).

Figura 4 - Jornal Correio da Manhã, Rio de Janeiro, n. 19, p. 2, 3 jul. 1901

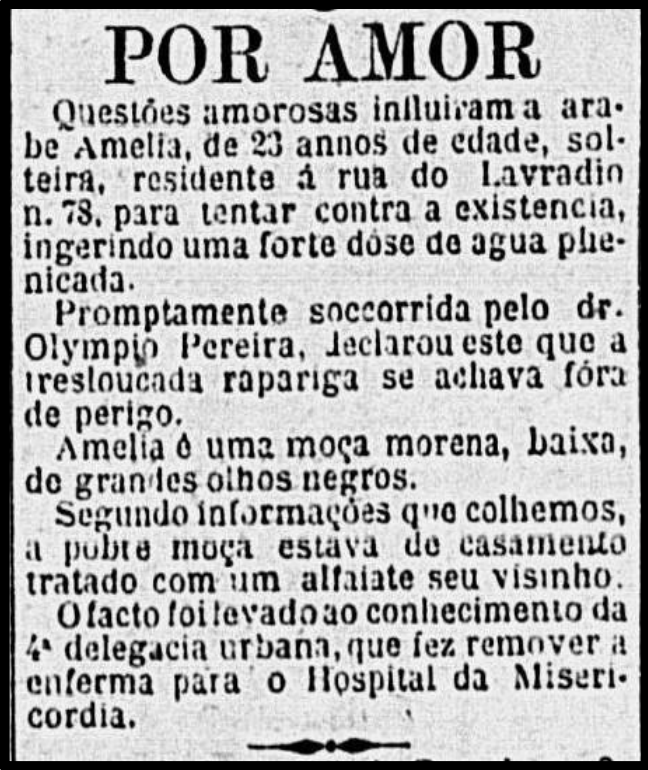

Fonte: Acervo da Hemeroteca Digital da Biblioteca Nacional, disponível em http://memoria.bn.br/DocReader/docmulti.aspx?bib=089842\&pesq=

Apesar de breve, tal narrativa também indica alguns dos elementos pelos quais se constituíam o arcabouço imagético e cultural que influía na caracterização da mulher e, também, do amor no contexto de transição do século XIX ao XX. O título, com letras grandes e maiúsculas, explicita a intencionalidade de chamar a atenção do leitor, antecipando as supostas motivações de Amélia e possibilitando inferir a presença da vinculação do relato a um imaginário romântico do suicídio.

A morte voluntária, especialmente a feminina, foi um artificio utilizado por autores canônicos dos Oitocentos como José de Alencar e Joaquim Manuel de Macedo. Segundo El Far 
(2004), nos populares romances de sensações também foram descritas sensacionalmente tragédias de mulheres que tiravam suas vidas, ou mesmo desistiam dela, entregando-se à morte passivamente. Sacrifícios ficcionais em nome da comoção e catarse de seus leitores, empregados, muitas vezes também, para demarcar a impropriedade de determinadas personagens femininas para alcançarem aquele que era lido enquanto o único espaço de realização da mulher: o casamento (EL FAR, 2004).

A loucura feminina demonstra-se, da mesma forma, fator de mobilização emocional também em razão das tensões que marcaram as disputadas de diferentes atores sociais pelos significados do feminino e do papel social da mulher na sociedade em transformação. A fragilidade da psique feminina e sua propensão à afetação emocional tresloucada figuraram na produção intelectual do período, que destinava vocações distintas para homens e mulheres, no que tange tanto à vida pública quanto privada, justificando-as por supostas características atávicas aos sexos biológicos (ESTEVES, 1989; SOIHET,1989; MARTINS, 2004; ENGEL, 2000). Nesse contexto, segundo Lopes (2003), muitos médicos e cientistas brasileiros concebiam as paixões patológicas como mais frequentes entre a porção feminina da população na qual "a paixão se tornaria mais viva, mais animada, e principalmente, mais erótica" (LOPES, 2003, p.124).

O último fait divers - "Acto de Desespero" (Figura 5) - sobre tentativas de suicídio, disposto na segunda página da edição 19 do Correio da Manhã, evidencia outra forma de abordagem do suicídio, consideravelmente mais indulgente, sobretudo se comparada à primeira reportagem.

Figura 5 - Jornal Correio da Manhã, Rio de Janeiro, n. 19, p. 2, 3 jul. 1901

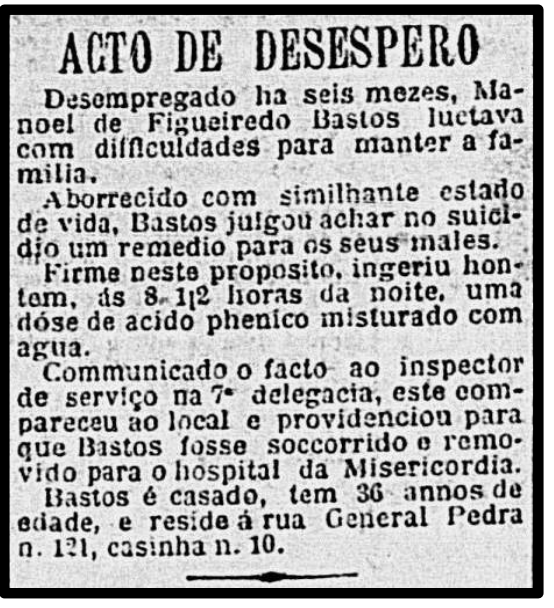

Fonte: Acervo da Hemeroteca Digital da Biblioteca Nacional, disponível em http://memoria.bn.br/DocReader/docmulti.aspx?bib=089842\&pesq= 
O sofrimento de Manoel é pautado, narrativamente, em motivações ligadas a uma realidade consideravelmente apreensível a todos e não por um ímpeto de embriaguez ou tresloucado sentimento. O relato chega a afirmar que Manuel teria encarado a morte como "um remédio" para seus males, referindo-se às supostas dificuldades que o suicida desempregado enfrentava para manter a família. A presença desse elemento como justificação de uma tragédia em faits divers viabiliza inferir que a representação do desemprego masculino tinha potencialidade para mobilizar o público. Possivelmente porque o público, em certo nível, concebesse o trabalho em termos moralizantes, e/ou conhecesse a repressão e o estigma que afligia cotidianamente àqueles que fossem considerados vadios. Destaca-se, nesse sentido, que a representação da desocupação e da vadiagem, tal como sua indefinição legal, não atingiu a sociedade sem contradições, incidindo distintamente entre diferentes grupos que compunham o corpo social.

Há contrastes no tratamento conferido às notícias das tentativas de suicídio de Benedicto e Manoel. A tentativa de suicídio do "creoulo" Benedicto é caracterizada pela notícia como “capoirismo", em uma referência à capoeira, prática então criminalizada e legalmente associada à vadiagem. ${ }^{7}$ Por sua vez, a suposta tentativa de suicídio de Manoel, um homem também sem ocupação, é caracterizada como uma ação desesperada. Manoel é redimido narrativamente pelo seu papel social de pai e pela sua inconformidade perante o desemprego, já Benedicto é execrado por seu consumo alcoólico, fator catalisador para a emersão de julgamentos a respeito de sua cor. Percebe-se, nesse sentido, que nas páginas do Correio da Manhã, é possível acesso a diferentes formas de representar transgressores e suas transgressões, mesmo entre aqueles do mesmo gênero.

Não obstante, conforme se pode observar na notícia a seguir, o potencial analítico de tal gênero jornalístico não se limita apenas a decifrar sua faculdade de divulgação de premissas de ordenamento social. A narrativa publicada em 4 de fevereiro de 1902, sob o título "Prisão Injusta" (Figura 6), aporta a percepção de uma possibilidade de subversão dos papéis sociais então estipulados para homens e mulheres a partir de teorizações de suas supostas diferenças naturais:

\footnotetext{
${ }^{7}$ No Código Penal de 1890, o capítulo XII, intitulado "Dos Vadios e Capoeiras", previa nos artigos 402, 403 e 404, a "capoiragem" como delito passível de punição penal (BRASIL, 1890).
} 
Figura 6 - Jornal Correio da Manhã, Rio de Janeiro, n. 235, p. 2, 4 fev. 1902

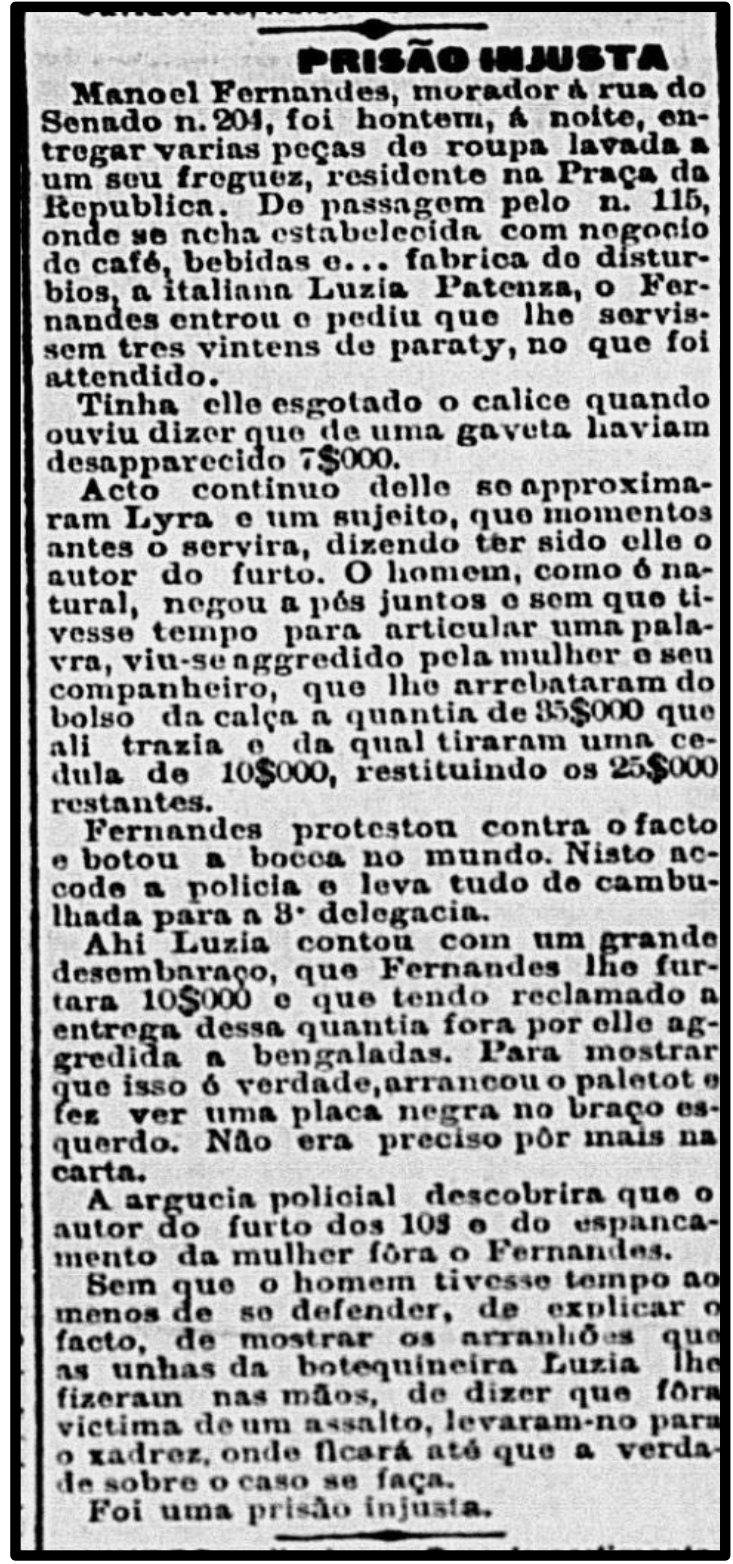

Fonte: Acervo da Hemeroteca Digital da Biblioteca Nacional, disponível em http://memoria.bn.br/DocReader/docmulti.aspx?bib=089842\&pesq=

Na noite anterior à publicação da matéria, o protagonista, Manoel Fernandes, foi preso sob a acusação de ter furtado $10 \$ 000$ e agredir Luzia Patenza. Segundo a notícia, após tomar três vinténs de cachaça no bar da italiana, referido no texto como uma "fábrica de desordens", o lavadeiro foi acusado por Luzia e seu "companheiro" de furtar o dinheiro. Mesmo antes que pudesse se explicar, Manoel teria sido agredido pelo casal, que lhe arrebatou das calças a quantia de $10 \$ 000$ (PRISÃO...4 fev. 1902, p. 2).

Mediante a confusão, a polícia teria aparecido e levado "a cambulhada" toda para a delegacia. Ao prestar sua versão do ocorrido, Luzia, com "grande desembaraço", não apenas 
teria reiterado sua acusação, mas também afirmou que quando o confrontou, Manoel a agrediu com bengaladas. No fim, e sem ter supostamente tido tempo de se defender ou mostrar os arranhões infligidos nele por Luzia, o suposto inocente homem foi jogado no "xadrez" (PRISÃO...4 fev. 1902, p. 2).

Não é possível estabelecer se de fato Luzia e seu companheiro agrediram Manoel. Afinal, a despeito da versão dos fatos publicados pelo jornal, é cabível que o homem tenha causado os hematomas da italiana. Igualmente difícil é estipular em que medida o episódio acima não foi ficcionalizado na própria redação do Correio. Contudo, a versão oferecida pelo jornal demonstra crível que, nesse contexto histórico, mesmo uma "desordeira" pudesse subverter a fragilidade então projetada a ela em função do seu suposto "sexo frágil", evocandoa para se livrar de seus crimes.

\section{Considerações finais}

Para além da simples cobertura de tragédias cotidianas, a mediação jornalística de episódios de transgressão demonstra-se perpassada por elementos de debates referentes a questões caras à sociedade em que foi produzida. A confecção de notícias criminais responde a uma série de fatores, sendo influenciada não apenas por um horizonte de expectativas simbólicas compartilhadas com gêneros de ficção sensacionais, mas, também, condicionada por elipses e aparições empregadas por repórteres de folhas empenhadas na conquista e manutenção de um público cativo. Assim sendo, os faits divers revelam-se como discursos permeáveis a artifícios folhetinescos próprios de formas populares de literatura e a projetos científicos de ordenamento social.

Por meio da análise dessas notícias, pode-se vislumbrar, no início do século XX, uma conjuntura em que anônimos cotidianamente tencionavam e, em alguns casos, até subvertiam os projetos de ordenamento sociais oriundos de teorizações a respeito do controle da degenerescência do tipo nacional. Afinal, ainda que algumas dessas notícias reproduzissem desqualificações de certos tipos sociais e modos de vida, evidenciaram, também, os próprios limites de algumas das idealizações estipuladas pelas concepções científicas, por exemplo, das supostas naturais disposições de homens e mulheres.

Em vários aspectos as trajetórias dos envolvidos nessas tragédias anônimas burlavam os parâmetros da boa conduta então divulgados pelos discursos de juristas, médicos e intelectuais. Nesse sentido, a análise historiográfica dessas narrativas desvela também indícios das ressignificações que faziam os cariocas, para burlar os ordenamentos higienistas de sua 
elite. Verifica-se, portanto, que o jornalismo, ao metamorfosear dados e discursos em m eio a esquemas folhetinescos e artifícios melodramáticos, pode compor textos que expõem sensacionalmente feridas sociais de seu contexto histórico.

\section{Referências}

ACTO de desespero. Correio da Manhã, Rio de Janeiro, edição n. 19, p. 2, 3 jul. 1901.

ADIALA, Júlio Cesar. Drogas, medicina e civilização na primeira república. 2011. Tese (Doutorado em História das Ciências e da Saúde) - Programa de Pós-Graduação em História das Ciências e da Saúde, Casa Oswaldo Cruz/Fiocruz, Rio de Janeiro, 2011. Disponível em: https://www.arca.fiocruz.br/handle/icict/17765. Acesso em: 25 abr. 2020,

ANGRIMANI, Sobrinho Danilo. Espreme que sai sangue. Um estudo do sensacionalismo na imprensa. São Paulo: Summus, 1995.

BARBOSA, Marialva. Imprensa, poder e público: os diários do Rio de Janeiro (1880-1920). Intercom - Revista Brasileira de Ciências da Comunicação, São Paulo, v. 20, n. 2, p. 87102, 1997. Disponível em:

http://www.portcom.intercom.org.br/revistas/index.php/revistaintercom/article/view/945.

Acesso em: 25 abr. 2020.

BARBOSA, Marialva. História cultural da imprensa: Brasil 1900 - 2000. Rio de Janeiro: Mauad X, 2007.

BARRETO, Lima. Recordações do escrivão Isaías Caminha. 10 ed. São Paulo: Editora Ática, 2008.

BARTHES, Roland. Ensaios críticos. Lisboa: Edições 70, 1997.

BRASIL. Decreto $\mathbf{n}^{\circ}$ 847, de 11 de outubro de 1890. Promulga o Código Penal. Rio de Janeiro, 1890. Disponível em: http://www.planalto.gov.br/ccivil_03/decreto/18511899/D847.htm. Acesso em: 27/04/2020

CHALHOUB, Sidney. Trabalho, lar e botequim: o cotidiano dos trabalhadores no Rio de Janeiro da Belle Époque. Campinas: Editora da Unicamp, 2001.

CHARTIER, Roger. A História Cultural entre práticas e representações. Rio de Janeiro: Bertrand Brasil, 1990.

CHARTIER, Roger. O mundo como representação. Estudos Avançados, [S. 1.], v. 5, n. 11, p. 173-191, 1991. Disponível em: https://www.revistas.usp.br/eav/article/view/8601. Acesso em: 8 jul. 2021.

El FAR, Alessandra. Páginas de sensação: literatura popular e pornográfica no Rio de Janeiro (1870-1924). São Paulo: Companhia das Letras, 2004. 
ENGEL, Magali Gouveia. Psiquiatria e feminilidade. In: PRIORE, Mary Del (org.). História das mulheres no Brasil. São Paulo: Contexto, 2000. p. 322 - 365.

ESTEVES, Martha de Abreu. Meninas perdidas: os populares e o cotidiano do amor no Rio de Janeiro da Belle Époque. Rio de Janeiro: Editora Paz e Terra, 1989.

FERRO, Marc. Présentation - Dossier Faits divers, faits d'histoire. Revue Annales: Histoire, Sciences Sociales, v. 38, n. 4, 1983. Disponível em: http://www.persee.fr/doc/ahess_03952649_1983_num_38_4_410962. Acesso em: 28 abr. 2017.

FLORES, Isadora Luiza Francisca Alves. Faits Divers: narrativas de transgressão e crime no Rio de Janeiro do início do século XX (1901-1904). 2018. Dissertação de Mestrado (Programa de Pós-Graduação Interdisciplinar em Estudos Latino-Americanos) - Universidade Federal da Integração Latino-Americana (Unila), Foz do Iguaçu, 2018.

GARZONI, Lerice de Castro. Nós, em nome do povo, cujo direito defendemos: o "Correio da Manhã" e a campanha contra as carnes verdes em 1901. In: SIMPÓSIO NACIONAL DE HISTÓRIA, 25., 2009, Fortaleza. Anais [...]. Fortaleza: ANPUH, 2009, p. 1-10. Disponível em: https://anpuh.org.br/uploads/anais-simposios/pdf/2019-

01/1548772006_f9cafb97ba45ce8246287b75ca8dcf50.pdf. Acesso em: 5 out. 2017.

GARZONI, Lerice de Castro. Disputas políticas e disputas por leitores: a criação do Correio da Manhã (1898-1901). Topoi, v. 12, n. 22, p. 158-177, 2011. Disponível em: https://www.scielo.br/j/topoi/a/wHxTwdgJ5Xy4xNFGDh8c8Tk/?format=pdf\&lang=pt. Acesso em: 23 mar. 2020.

GUIMARÃES, Valéria. Sensacionalismo e modernidade na imprensa brasileira no início do século XX. Revista ArtCultura, v. 11, n. 18, p. 227-240, jan./jun. 2009. Disponível em: https://seer.ufu.br/index.php/artcultura/article/view/7315. Acesso em: 24 fev. 2016.

GUIMARÃES, Valéria. A Revista Floreal e a recepção aos faits divers na virada do dezenovevinte. Revista Galáxia, São Paulo, n. 19, p. 274-290, jul. 2010. Disponível em: https://revistas.pucsp.br/index.php/galaxia/article/view/2984/2209. Acesso em: 24 mar. 2020.

GUIMARÃES, Valéria. Notícias diversas: suicídios por amor, 'leituras contagiosas' e cultura popular em São Paulo nos anos dez. São Paulo: Mercado das Letras, 2013.

GUIMARÃES, Valéria. Primórdios da história do sensacionalismo no Brasil: os faits divers criminais. Revista ArtCultura, Uberlândia, v. 16, n. 29, p. 103-124, jul./dez. 2014. Disponível em: https://seer.ufu.br/index.php/artcultura/article/view/34324. Acesso em: 24 mar. 2020.

LOPES, Fabio Henrique. A experiencia do suicidio: discursos medicos no Brasil, 1830-1900. 2003. 223 p. Tese (doutorado) - Universidade Estadual de Campinas, Instituto de Filosofia e Ciencias Humanas, Campinas, SP. Disponível em: https://bdtd.ibict.br/vufind/Record/CAMP_062315138613f37a623179bdf032e3aa. Acesso em: 02 set. 2018.

MARTINS, Ana Luiza; De LUCA, Tânia Regina. Imprensa e cidade. São Paulo: UNESP, 2006. 
MARTINS, Ana Paula Vosne. Visões do feminino: a medicina da mulher nos séculos XIX e XX. Rio de Janeiro: Editora FIOCRUZ, 2004.

MEYER, Marylse. Folhetim: uma história. São Paulo: Companhia das Letras, 1996.

MULHER aggredida - A navalha - Em Bemfica. Correio da Manhã, Rio de Janeiro, edição n. 605, p. 2, 6 fev, 1903.

PESAVENTO, Sandra Jatahy. Cultura e representações: uma trajetória. Anos 90, Porto Alegre, v. $13, \quad$ n. $23, \quad$ p. 45-58, jan./dez, 2006. Disponível em: https://seer.ufrgs.br/anos90/article/view/6395. Acesso: 24 abr. 2020.

POR amor. Correio da Manhã, Rio de Janeiro, edição n. 19, p. 2, 3 jul. 1901.

PRISÃO injusta. Correio da Manhã, Rio de Janeiro, edição n. 235, p. 2, 4 fev. 1902.

TENTATIVA de suicídio. Correio da Manhã, Rio de Janeiro, edição n. 19, p. 2, 3 jul. 1901.

SCHWARCZ, Lilia Moritz. O espetáculo das raças. Cientistas, instituições e questão racial no Brasil, 1870-1930. 6. e.d. São Paulo: Companhia das. Letras, 2005.

SODRÉ, Nelson Werneck. História de imprensa no Brasil. 4. ed. Rio de Janeiro: Mauad, 1999.

SOIHET, Rachel. Condição Feminina e formas de violência: mulheres pobres e ordem urbana 1890-1920. Rio de Janeiro, Forense Universitária. 1989.

Submetido em: 16.05.2020.

Aprovado em: 07.12.2021. 